\title{
Varietal Identification Based on Chemical Methods in Different Varieties of Indian Mustard (Brassica juncea (L.) Czern. \& Coss.)
}

\author{
Himanshu Rai*, Ovais Hamid Peerzada, O.S. Dahiya and S.S. Jakhar \\ Department of Seed Science \& Technology, Chaudhary Charan Singh Haryana Agriculture \\ University, Hisar - 125004 (Haryana), India \\ *Corresponding author
}

\section{A B S T R A C T}

\begin{tabular}{|c|}
\hline Keywords \\
\hline $\begin{array}{l}\text { Indian mustard, } \\
\text { Phenol, KOH, } \\
\text { NaOH, Peroxiase } \\
\text { and 2, 4-D Auxin }\end{array}$ \\
\hline Article Info \\
\hline $\begin{array}{l}\text { Accepted: } \\
18 \text { April } 2019 \\
\text { Available Online: } \\
10 \text { May } 2019\end{array}$ \\
\hline
\end{tabular}

The study was conducted during 2014-15 and 2015-16 at the laboratories of the Department of Seed Science \& Technology, CCS HAU, Hisar, to distinguish twenty Indian mustard varieties/genotypes based on chemical tests (phenol, modified phenol, $\mathrm{KOH}, \mathrm{NaOH}$, Peroxidase and 2, 4-D Auxin). Phenol test grouped variety into three distinct groups viz., dark reddish brown (12 varieties), dark grey (6 varieties) and Dark red (2 varieties). With the help of modified phenol test these varieties were further sub grouped. $\mathrm{KOH}$ test grouped varieties into three distinct groups i.e., dark brown (6 varieties), brown ( 5 varieties) and light brown (9 varieties). These tests clearly differentiated the varieties of one group to that of another groups on the basis of seed coat colour. $\mathrm{NaOH}$ test was not reliable for the differentiation of these varieties because all these varieties showed dark brown colour after treating with $\mathrm{NaOH}$ solution. Peroxidase test categorized varieties into three groups viz., high (9 varieties), medium (8 varieties), and (3 varieties) while 2, 4-D Auxin test grouped the varieties into three categories viz., tolerant (4 varieties), susceptible (8 varieties) and highly susceptible (8 varieties).

\section{Introduction}

In India crop specific large number of crop improvement programmes are running and with the result of this a large number of varieties are being developed.

Thus varietal identification becomes an essential issue to maintain the genetic purity and identity of each variety. Indian musturd (Brassica juncea) belongs to the Cruciferae (Brassicaceae) family. In India, the Brassica oilseed is collectively referred to as rapeseedmustard, which is the most important Rabi oilseed crop and occupies an important position in the rain fed agriculture of our country.

The aspect of Distinctness, Uniformity and Stability (DUS) is fundamental for characterization of varieties. Accurate identification of varieties is not only a pre requisite for DUS testing, but is critical for the production of quality seed also. Maintenance of genetic purity of varieties is of primary importance for preventing varietal deterioration during successive regeneration cycles and for ensuring varietal performance 
at an expected level. Laboratory tests have several additional benefits for varietal identification. These chemical tests are very quick, easy to do, reproducible and can be conducted throughout the year under controlled conditions.

Some of the popular chemical tests used in Indian mustard for varietal characterization are phenol test, modified phenol test $\left(\mathrm{CuSO}_{4}\right.$ and $\left.\mathrm{Na}_{2} \mathrm{CO}_{3}\right)$, sodium hydroxide $(\mathrm{NaOH})$ test, peroxidase test, potassium hydroxide $(\mathrm{KOH})$ test and 2, 4-D auxin test. The chemical tests reveal differences of colour among the seeds. Study of phenotypic characters along with chemical and biochemical techniques have additional benefits for producing more authentic result. In these chemical tests, the chemical agents react with the seed and help in varietal identification.

\section{Materials and Methods}

The freshly harvested Seed of all the twenty Indian mustard varieties were used for varietal identification. The experiment was conducted at the laboratories of Department of Seed Science and Technology during the period of 2014-15 and 2015-16. The list of varieties and their source is given below:

\section{Phenol test}

The Standardized phenol test for varietal purity testing as suggested by walls (1965) was followed. The procedure consisted of soaking the seed in water for $16 \mathrm{~h}$ under ambient condition and then 50 seeds in $15 \mathrm{~cm}$ petridishes in two layers of filter soaked in $1 \%$ phenol solution in three replications. The seeds were placed on filter paper with hilum region on the down side. The petridishes were immediately covered. A final observation was made after $6 \mathrm{~h}$. The following three distinct phenol colour reaction group were made dark reddish brown, dark grey and dark red.

\section{Modified phenol test}

Modified phenol test was followed as described by Banerjee and Chandra (1977). 50 seeds were soaked in 0.4 per cent solution of $\mathrm{CuSO}_{4}$ for adding $\mathrm{Cu}^{++}$ions and another set in 0.6 per cent $\mathrm{Na}_{2} \mathrm{CO}_{3}$ for adding $\mathrm{Na}+$ ions for 4 $\mathrm{h}$. Then the seeds were placed in 2 per cent phenol solution after removing from the $\mathrm{CuSO}_{4}$ and $\mathrm{Na}_{2} \mathrm{CO}_{3}$ solution overnight. Based on the colour development in both the tests groups were made and classified in to three groups dark brown, brown and reddish brown colour in $\mathrm{CuSO}_{4}$ soaked seed, were classified in to three groups brown, dark brown and strong brown for $\mathrm{Na}_{2} \mathrm{CO}_{3}$ soaked seeds.

\section{Potassium Hydroxide (KOH) test}

Hundred seeds in three replications were soaked in five per cent $\mathrm{KOH}$ solution for two $\mathrm{h}$ at room temperature. Changes in colour of the seeds were observed after one h. Based on the colour intensity of the seed, the genotypes were classified into three group's viz., dark brown, reddish brown and light brown (Agrawal and Pawar, 1990).

\section{Sodium Hydroxide ( $\mathrm{NaOH})$ test}

Hundred seeds in three replications were soaked in five per cent $\mathrm{NaOH}$ solution for one $\mathrm{h}$ at room temperature. Changes in colour of the seeds were observed after one h. Based on the colour intensity of the seed, the genotypes were classified into three group's viz., Dark brown, Light brown and Brown.

\section{Peroxidase test}

Under this test, 60 seed were soaked in water for $24 \mathrm{~h}$ after that 15 seeds were incubated in $2.5 \mathrm{ml}$ of guaiacol solution $(0.05 \%)$ for 20 minutes. $2 \mathrm{ml}$ of guaiacol was taken out and $0.2 \mathrm{ml}$ of $\mathrm{H}_{2} \mathrm{O}_{2}(0.1 \%)$ was added. In this reddish brown coloured appeared which was 
quantified by DU 64 spectrophotometer at 480 $\mathrm{nm}$. The reading was taken after two minutes of adding the $\mathrm{H}_{2} \mathrm{O}_{2}$ in guaiacol. The whole test was carried out at $25^{\circ} \mathrm{C}$ on basis of transmittance per cent.

\section{2, 4-D Auxin test}

The effect of 2, 4-D test at 5ppm concentration on seedling was studied. For this 20 seeds were grown by placing them on two layers of filter paper moistened in 2, 4-D auxin in the petridishes. The petridishes were kept in germinator at $25^{\circ} \mathrm{C}$. Seedlings were evaluated after 7days and ten seedling were selected at random and seedling length (shoot length + root length) was measured in Centimetres.

\section{Results and Discussion}

In the present experiment, twenty Indian mustard varieties were characterized on the basis of different chemical tests (Table 1).

\section{Phenol test and modified phenol test}

Phenol test showed great variation among varieties into light brown, brown and dark brown group (Table 1). This test is highly specific for varieties. Phenol reaction is monogenically controlled response, which is present in seed coat (Joshi and Banerjee, 1970).

An enzyme polyphenol oxidase (PPO) is responsible for the oxidation of externally supplied phenol into quinones and their further polymerization yield melanin like pigments which have resulted in development of brown colouration in seeds. So seed coat colour development in Indian mustard seed coat by phenol colour reaction is detected and varieties were differentiated as dark reddish brown, dark grey, dark red. Out of 20 varieties twelve varieties viz., RH30, RH8812,
RH8113, RH0749, RH0119, RH9801, RH819, NRCDR601，DRMRIJ31，NPJ112，RGN73 and Kranti showed dark reddish brown, six i.e., RB50, RH0406, RH9304, Varuna, NRCDR02, and NRCHB101 showed dark grey and rest two varieties RB24 and RH781 had dark red colouration.

The results are in conformity with findings of Jawaharlal (1994), Ezhilkumar (1999), Ponnuswamy et al., (2003) and Reddy (2004) in cotton and Rana (2006) in cluster bean.

Further modified phenol $\left(\mathrm{CuSO}_{4} \quad 0.4 \%\right.$ and $\mathrm{NA}_{2} \mathrm{CO}_{3} 0.6 \%$ as a inhibitor) is used for better result and sub grouping of the varieties in different groups.

Both phenol and modified phenol is emerging as a stable and uniform method for grouping of Indian mustard varieties. Similar observations were recorded by Gupta et al., (2007) in wheat and Anitalakshmi et al., (2014) in rice.

\section{Potassium hydroxide (KOH) test}

On the basis of colour reaction with potassium hydroxide solution, the Indian mustard varieties were grouped into dark brown, brown and light brown (Table 1).

Among the 20 varieties, six varieties, RH8113， RH0406， RH819， NRCDR02, NRCHB601 and NPJ112 showed dark brown colour, five varieties, RH0749, RB24, RH9304, NRCHB101 and Varuna showed brown colour and nine, varieties, RH30, RH8112, RB50, RH0119, RH9801, RH781, DRMRIJ31, RGN73 and Kranti had light brown colouration.

Same type of results was revealed by Sivakumar (2002) in cluster bean, Sambasiva Rao et al., (2002) in groundnut and Biradarpatil et al., (2006) in safflower. 
Table.1 Categorization of Indian mustard varieties on the basis of Chemical approach (pooled data)

\begin{tabular}{|c|c|c|c|c|c|}
\hline Variety & $\begin{array}{l}\text { Phenol test } \\
(1 \%) \text { after } \\
6 \text { hours }\end{array}$ & $\begin{array}{l}\text { Modified phenol } \\
\left(\mathrm{CuSo}_{4} 0.4 \%\right) \\
\text { after } 4 \text { hours. }\end{array}$ & $\begin{array}{l}\text { Modified phenol } \\
\left(\mathrm{NA}_{2} \mathrm{CO}_{3} 0.6 \%\right) \\
\text { after } 4 \text { hours }\end{array}$ & $\begin{array}{l}\text { Potassium hydroxide } \\
(0.5 \%) \text { after } 4 \text { hours }\end{array}$ & $\begin{array}{l}\text { Sodium hydroxide } \\
(0.5 \%) \text { After } 4 \text { hour }\end{array}$ \\
\hline RH30 & Dark reddish brown & Brown & Brown & Light brown & Dark brown \\
\hline RH8812 & Dark reddish brown & Dark brown & Dark brown & Light brown & Dark brown \\
\hline RH8113 & Dark reddish brown & Dark brown & Dark brown & Dark brown & Dark brown \\
\hline RH0749 & Dark reddish brown & Brown & Brown & Brown & Dark brown \\
\hline RB50 & Dark grey & Brown & Brown & Light brown & Dark brown \\
\hline RH0406 & Dark grey & Dark brown & Dark brown & Dark brown & Dark brown \\
\hline RB24 & Dark red & Brown & Brown & Brown & Dark brown \\
\hline RH0119 & Dark reddish brown & Reddish brown & Light brown & Light brown & Dark brown \\
\hline RH9304 & Dark grey & Brown & Brown & Brown & Dark brown \\
\hline RH9801 & Dark reddish brown & Reddish brown & Light brown & Light brown & Dark brown \\
\hline RH819 & Dark reddish brown & Strong brown & Strong brown & Dark brown & Dark brown \\
\hline RH781 & Dark red & Reddish brown & Light brown & Light brown & Dark brown \\
\hline Varuna & Dark grey & Brown & Brown & Brown & Dark brown \\
\hline NRCDR02 & Dark grey & Dark brown & Dark brown & Dark brown & Dark brown \\
\hline NRCDR601 & Dark reddish brown & Strong brown & Strong brown & Dark brown & Dark brown \\
\hline NRCHB101 & Dark grey & Dark brown & Dark brown & Brown & Dark brown \\
\hline DRMRIJ31 & Dark reddish brown & Brown & Brown & Light brown & Dark brown \\
\hline NPJ112 & Dark reddish brown & Dark brown & Dark brown & Dark brown & Dark brown \\
\hline RGN73 & Dark reddish brown & Reddish brown & Light brown & Light brown & Dark brown \\
\hline Kranti & Dark reddish brown & Strong brown & Strong brown & Light brown & Dark brown \\
\hline
\end{tabular}

\begin{tabular}{|c|c|c|c|c|}
\hline Variety & Peroxidase test $(\%)$ & Groups & 2,4-D auxin test $(\mathrm{cm})$ & Groups \\
\hline RH30 & $39.00(38.63)$ & Low & 1.4 & High susceptible \\
\hline RH8812 & $51.00(45.56)$ & High & 1.8 & Susceptible \\
\hline RH8113 & $38.00(38.03)$ & Low & 1.6 & Susceptible \\
\hline RH0749 & $48.00(43.84)$ & Medium & 2.6 & Tolerant \\
\hline RB50 & $69.00(56.18)$ & High & 1.3 & High susceptible \\
\hline RH0406 & $38.00(38.04)$ & Low & 2.3 & Tolerant \\
\hline RB24 & $41.00(39.80)$ & Medium & 1.4 & High susceptible \\
\hline RH0119 & $69.50(56.46)$ & High & 1.5 & Susceptible \\
\hline RH9304 & $47.00(43.26)$ & Medium & 1.7 & Susceptible \\
\hline RH9801 & $48.00(43.84)$ & Medium & 1.3 & High susceptible \\
\hline RH819 & $61.00(51.34)$ & High & 2.5 & Tolerant \\
\hline RH781 & $51.50(45.84)$ & High & 2.4 & Tolerant \\
\hline Varuna & $55.00(47.85)$ & High & 1.4 & High susceptible \\
\hline NRCDR02 & $61.00(51.35)$ & High & 1.7 & Susceptible \\
\hline NRCDR601 & $43.00(40.96)$ & Medium & 1.3 & High susceptible \\
\hline NRCHB101 & $62.00(51.93)$ & High & 1.4 & High susceptible \\
\hline DRMRIJ31 & $56.00(48.43)$ & High & 1.8 & Susceptible \\
\hline NPJ112 & $41.00(39.79)$ & Medium & 1.6 & Susceptible \\
\hline RGN73 & $42.50(40.67)$ & Medium & 1.5 & Susceptible \\
\hline Kranti & $44.50(41.83)$ & Medium & 1.4 & High susceptible \\
\hline Mean & 50.30 & - & 1.7 & - \\
\hline Range & $38-69.50$ & $\begin{array}{c}\text { High- 51-69.50 } \\
\text { Medium-41-48 } \\
\text { Low- 38-39 }\end{array}$ & 1.3 to 2.6 & $\begin{array}{c}\text { Tolerant-2.3-2.6 } \\
\text { Susceptable-1.5-1.8 } \\
\text { High susceptible-1.3-1.4 }\end{array}$ \\
\hline $\mathrm{SE}(\mathrm{m})$ & $1.30(0.77)$ & & 0.1 & \\
\hline C.D. & $3.72(2.20)$ & & 0.3 & \\
\hline
\end{tabular}


Source of Seed: Seed of 20 Indian mustard varieties

\begin{tabular}{|c|c|c|c|c|c|}
\hline Variety & Source & Variety & Source & Variety & Source \\
\hline RH30 & $\begin{array}{c}\text { CCSHAU, } \\
\text { Hisar }\end{array}$ & RH0119 & CCSHAU, Hisar & NRCDR601 & DRMR Bharatpur \\
\hline RH8812 & $\begin{array}{c}\text { CCSHAU, } \\
\text { Hisar }\end{array}$ & RH9304 & CCSHAU, Hisar & NRCHB101 & DRMR Bharatpur \\
\hline RH8113 & $\begin{array}{c}\text { CCSHAU, } \\
\text { Hisar }\end{array}$ & RH9801 & CCSHAU, Hisar & DRMRIJ31 & DRMR Bharatpur \\
\hline RH0749 & $\begin{array}{c}\text { CCSHAU, } \\
\text { Hisar }\end{array}$ & RH819 & CCSHAU, Hisar & NPJ112 & IARI, New Delhi \\
\hline RB50 & $\begin{array}{c}\text { CCSHAU, } \\
\text { Hisar }\end{array}$ & RH781 & CCSHAU, Hisar & RGN73 & $\begin{array}{c}\text { RAU, } \\
\text { Sriganganagar }\end{array}$ \\
\hline RH0406 & $\begin{array}{c}\text { CCSHAU, } \\
\text { Hisar }\end{array}$ & Varuna & $\begin{array}{l}\text { CSAUA\&T } \\
\text { Kanpur }\end{array}$ & Kranti & $\begin{array}{l}\text { GBPUA\&T, } \\
\text { Pantnagar }\end{array}$ \\
\hline RB24 & $\begin{array}{c}\text { CCSHAU, } \\
\text { Hisar }\end{array}$ & NRCDR02 & $\begin{array}{c}\text { DRMR } \\
\text { Bharatpur }\end{array}$ & & \\
\hline
\end{tabular}

\section{Sodium hydroxide $(\mathrm{NaOH})$ test}

The colour reaction with sodium hydroxide solution grouped the Indian mustard varieties into dark brown colour (Table 1). The seeds soaked in $\mathrm{NaOH}$ solution reacted variedly based on the chemical compositions of the seed, which is determined by the genetic makeup of the varieties and hence variation in colour was observed. Among all varieties (RH30, RH8812, RH8113, RH0749, RB50, RH0406, RB24, RH0119, RH9304, RH9801, RH819, RH781, Varuna, NRCDR02, NRCDR601, NRCHB101, DRMRIJ31, NPJ112, RGN73 and Kranti) showed dark brown colouration. Similar results were reported by Biradarpatil et al., (2006) in safflower, Singh (2001) in chickpea and Ali (2005) in soyabean.

\section{Peroxidase test}

The general mean value for peroxidase was 50.30 (50\%) with a range varied from 3869.50.Three groups were made on the basis of peroxidase activity (Table 1). Nine i.e., RH0119 (69.50), RB50 (69.00), NRCHB101 (62.00), RH819 (61.00), NRCDR02 (61.00), DRMRIJ31 (56.00), Varuna (55.00), RH781 (51.50) and RH8812 (51.00), eight i.e., RH0749 (48.00),
RH9801 (48.00), RH9304 (47.00), Kranti (44.50), NRCDR601 (43.00), RGN73 (42.50), RB24 (41.00) and NPJ112 (41.00) and three varieties i.e., RH30 (39.00), RH8813 (38.00) and RH0406 (38.00) had high, medium and low peroxidase activities respectively (Table 1 ).

\section{2, 4-D auxin test}

Variation in seedling growth response to 2, 4-D was due to inhibition of seedling growth and other activity. Significant differences were observed among the varieties with respect to 2 , 4-D application and classified into tolerant, susceptible and highly susceptible (Table 1). Out of 20 varieties four i.e., RH0749 (2.6), RH819 (2.5), RH781 (2.4) and RH0406 (2.3) were tolerant, eight i.e., RH8812 (1.8), DRMRIJ31 (1.8), RH9304 (1.7), NRCDR02 (1.7), RH8113 (1.6), NPJ112 (1.6), RH0119 (1.5), and RGN73 (1.5) were susceptible and eight i.e., RH30 (1.4), RB24 (1.4), Varuna (1.4), NRCHB101 (1.4), Kranti (1.4), RB50 (1.3), RH9801 (1.3) and NRCDR601 (1.3) were highly susceptible. The differences in seedling growth reduction among the varieties might be due to differences in ethylene production because of application of 2, 4-D. Similar findings were reported by Biradarpatil (2006) in 
safflower, Shivakumar. (2000) in rapeseed and mustard and Sambasivarao (2002) in groundnut.

\section{References}

Agrawal, R.L., Pawar, A. 1990. Identification of soybean varieties based on seed and seedling characteristics. Seed Research, 18:77-81.

Ali, M.N. 2005. Cultivar identification in soybean M.Sc. Thesis, CCS HAU, Hisar.

Anitalakshmi, V., Gowda, R, C.S., Sathisha and Prasad, Rajendra. 2014. Varietal response to various chemical tests for their characterization in rice. Indian Journal of Plant Sciences, 3 (2): 177- 179.

Banerjee, S.K. and Chandra, S. 1977. Modified phenot test for the varietal identification of wheat seed, Seed Science \& Technology. 5: 53-60.

Biradarpatil, N.K., sangeeta, Macha, Motagi, B.N., Vijaykumar, A.G. and Hanchinal, R.R. 2006. Characterization of safflower varieties through chemical tests. Abstract XII National Seed Seminar, 24-26 February, ANGRAU Hyderabad, pp. 168.

Ezhilkumar, S. 1999. Studies on varietal identification in hybrids, parents and varieties in cotton (Gossypium spp.). $M$. Sc. (Agri.) Thesis, Tamil Nadu Agric. Univ., Coimbatore (India).

Gupta, Namarta, Joshi, Monika, A., Sarao, Navraj K. and Sharma, R.C. 2007. Utility of phenol test in varietal characterization. Crop Improvement 34 (1): 77-81.

Jawaharlal. 1994. Studies on varietal characterization in inbred, hybrids and varieties of cotton (Gossypium spp.) through physical, physiological and biochemical methods. M.Sc. (Agri.) Thesis, Tamil Nadu Agric. Univ.,
Joshi, M.G. and Banerjee, S.K. 1970. Genetics of phenol colour reaction in emmer wheat. Proceeding International. Seed Association. 35: 207.

Ponnuswamy, A.S., Bhaskaran, M. and Sastri, G. 2003, Variety characterization in cotton by physical, chemical and biochemical methods. Training Mannual, Variety characterization by image analysis and electrophoresis, pp. 106120.

Rana, R., 2006. Characterization and vigour assessment of cluster bean [Cyamopsis tetragonoloba (L.) Taub.] M.Sc. Thesis, CCS HAU, Hisar.

Reddy, K. C., 2004. Studies on laboratory techniques for identification of cotton (Gossypium spp.) genotypes. M. Sc. (Agri.) Thesis, Acharya N. G. Ranga Agric. Univ., Hyderabad (India).

Sambasivarao, P. Muralimohanreddy, B., Bharathi, M. and Bayyapu Reddy, K., 2002. Varietal identification in groundnut (Arachis hypogaea L.) by chemical tests and electrophoresis of total soluble seed proteins. Seed Tech News, 32(1): 93.

Shivakumar, 2000. Characterization of rapeseed and mustard (Brassica spp.) cultivars using field and laboratory techniques. Seed Tech News, 31 (1):31.

Singh, R., 2001. Characterization of chickpea cultivars by field and laboratory techniques. Ph.D. Thesis. CCS Haryana Agricultural University, Hisar.

Sivakumar, S., 2002. Characterization of cluster bean [Cyamopsis tetragonoloba (L.) Taub.]. M.Sc. Thesis, CCS HAU, Hisar.

Walls, F.W., 1965. A standardized phenol method for testing wheat for varietal purity. Handbook on seed testing, AOSA, Contribution No. 28.

\section{How to cite this article:}

Himanshu Rai, Ovais Hamid Peerzada, O.S. Dahiya and Jakhar, S.S. 2019. Varietal Identification Based on Chemical Methods in Different Varieties of Indian Mustard (Brassica juncea (L.) Czern. \& Coss.). Int.J.Curr.Microbiol.App.Sci. 8(05): 2391-2396. doi: https://doi.org/10.20546/ijcmas.2019.805.283 